\title{
ENCAPSULATING REAL-LIFE EXPERIENCE
}

\author{
David Kelly \& Bill Davey \\ RMIT University, Melbourne, Australia \\ David.Kelly@rmit.edu.au Bill.Davey@rmit.edu.au
}

Abstract In this paper we discuss experiences with work-situated learning and difficulties that commonly arise. The alternative of encapsulating real life experience in hypermedia based materials is then presented using a number of case studies. Finally a model is presented for producing these "real life" encapsulations which overcomes the problems of lack of structure in individual experience without losing the advantages of common lifelike experiences. Some testing of the model is presented. The model involves the steps of:

- Determine real life skills commonly required

- imagine a context rich enough (and having the case study design team with enough knowledge of the context that they can draw from their experience to fill in the holes)

- structure (partition) the case so that team work is possible without too much overlap between tasks. Identify the overlapping points that will force the level of teamwork between students that is intended

- identify parts of the solution development where students can be synchronised using a published solution to part of the problem

- create answers for each skill point starting from the top

- tag each part of the answer with the essential component of information required for an answer

- determine the most likely format that the tagged information would be found in real life

- create the set of tagged information using unskilled labour to provide detailed data

- write the project brief so that an appropriate level of guidance is given for navigating the information sources.

Keywords: Data model, business context, case study, virtual organisation, system analysis. 


\section{INTRODUCTION}

Weisman and Anthony (1999) concluded that there are four ways that knowledge is transferred: involvement (participation in learned organizations such as trade societies), association (formal or informal interactions with others), experience (knowledge acquired through implicit learning), and direct education (formal learning pursuits). A study by Simmonds et al. (2001) concluded that: "In general, results suggest that the primary source of management concepts for practicing managers is experience, followed by association and involvement. The least identified knowledge source for practicing managers was direct education."

If we are to make this last and least effective learning environment more effective we must make the learning environment more closely reflect real experience. One aspect of learning through experience is that all learning "on the job" is, by definition, useful.

Usefulness implies ways of resolving a problem through clarification, alternation, or actual solution and is based on an attitudinal perception of the effectiveness of applying specific information to resolve a problem or to make a decision. Other views of usefulness of education included those of Mangaliso and Choo. "Information is useful if it is appropriate for the situation in which it is used" (Mangaliso, 1995). Choo (1998) contends that "selection of information depends on the degree of relevance the user attributes to the information."

Using these views of education the designer of learning experiences is convinced to have at least some aspect of their delivery through a simulation as close to real as possible. There is a long history of using computers to provide simulations of learning situations where the real experience is not available or too expensive or dangerous. These are often linear experiences for students. Maddux has pointed to the essential weakness of linear experiences encapsulated in a computer delivered experience. "But typically, behavioural models of computer programmed instruction have several weaknesses: first, isolating factual information; second, learning in isolation; third, a linear structure that cannot match some learning activities; and fourth, lack of flexibility and user-friendliness" (Maddux et al., 1997, p.7677).

\section{SYSTEMS ANALYSIS AS A TOPIC}

Teaching of systems analysis often is reduced to identifying specific skills and then designing tasks based on text descriptions of a case to be analysed. These text-based case studies can degenerate into a written 
comprehension test. Students can achieve the intended result by "finding the answers" in the text. Systems analysis in a real life situation involves obtaining information about the site in a number of ways. These include the project brief, interviews, document analysis and observation of the current system. These applied tasks can be described as the capabilities of a graduate of a systems analysis course. If we are to teach real life capabilities then we must prepare assessment tasks that incorporate these real life characteristics. In real cases the information required to properly specify the problem will come from a mixture of these sources. Clearly a simulation of the process of systems analysis is fertile ground for use of multimedia delivery of the case study. A basic assumption of the techniques reported here is that "Knowledge is defined as a dynamic concept: Knowledge is only knowledge when it can be applied" (Weert 2003). Here we address the possibilities of encapsulating real life experiences in a web-based hypermedia experience for students and argue that the benefits of a controlled environment outweigh the lack of reality still inherent in the hypermedia.

\section{SYSTEMS ANALYSIS AS AN EXEMPLAR EDUCATIONAL AREA}

At RMIT University in Australia the teaching group charged with delivering education in systems analysis hit this need for relevance and experience as a major hurdle. Systems analysis involves searching through the miasma of complexity of a normal human organization to discover problem definitions that are amenable to analysis. Often the skills involved are required to be learnt by undergraduate students with superficial understandings of organizations typical of the consumer rather than even a junior employee of an organization. Skills such as recognising raw data to be relevant, obtaining data from a wide variety of sources including interviews and document analysis can be taught in isolation, but the transfer of these skills in a real situation seemed very poor. Transfer of knowledge to real situations was studied. Crucial factors that were not components of the learning experience were identified. These included:

- In real life different members of an organization see a given problem in different ways. The analyst is often presented with conflicting views of what the job is that they have been asked to analyse.

- Information in real organizations is "hidden" in a multitude of places and formats; in employee memory, in documents, in procedure manuals, in policy statements, in daily practice. 
- The information needed for analysis is "hidden" amongst large amounts of data that is of no relevance to the problem to be analysed. None of the data is tagged "relevant" or "not relevant"

- Real problems have a time and resource limit that has no bearing on the size or complexity of the problem. Problems are not tailored for a certain amount of time that is reasonable in terms of a thorough solution. This forces a problem solver to compromise quality of the solution to the resources available

\section{HYPERMEDIA AND THE WEB}

Gayeski defines hypermedia as a classification of software programs which consist of networks of related text, graphics, audio-files, and video clips through which users navigated by browser (Gayeski 1993). Such a definition of hypermedia seems to include all the facilities that allow a learning environment to reflect the complexity of real life. This advantage is in addition to those claimed by the literature for all hypermedia-based learning. For example (Liaw 2001) makes three claims for the advantages of hypermedia: "In the building of hypermedia instruction, four advantages of this learning environment emerge: multiple perspectives, collaborative learning, learner-orientation, and interdisciplinary learning." The use of collaborative learning environments provides a means to create more engaging and dynamic instructional settings (Slavin 1992). Collaboration can help individuals to make progress through their zone of proximal development by the activities in which they engage (Vygotsky 1978) Authors have also recognised the potential for hypermedia-based systems to show the dynamism that characterises real life situations. Typically, in formal schooling, much content quickly becomes "inert" while processed and integrated (Gagne et al. 1993), as it has little relevance to the life circumstance of the learners.

\section{COMPLEXITY AND HYPERMEDIA}

An underlying assumption of our work here should be stated explicitly. The teachers of systems analysis are in common accord as to one of the underlying requirements of professionals. The very need to perform systems analysis assumes that real systems have very detailed complexity. This complexity defeats many of the reductionist attitudes to classroom experience design. In a classroom of the past a teacher would attempt to look into a situation with a view to determining the simple principles to be 
attained by students. Experiences would then be designed that present those principles in as stark a situation as possible. Teaching of systems analysis is the antithesis of this process as students must be trained to find the principles from amongst the vast array of complex detail, most of which will be discarded deliberately in the systems analysis process. Liaw has expressed this essential skill of the real life partitioner. "Today, the problem is not so much in finding information but sifting through the huge amount that is readily available and locating the particular pieces that are of most interest at the moment" (Liaw 2001).

\section{WHY PRODUCE CASE STUDY SIMULATIONS}

The systems analysis team started in 1989 producing traditional case study material on paper in text. These "case studies" were descriptions of organizations where the text description contains ALL the information a student needs to produce the analysis and in approximately the right order. The team was dissatisfied with the process of learning that students demonstrated. A study of the literature found many principles that might be included in a new approach. For example Lee had concluded that "The modern computer technology has made possible a new and rich learning environment: the simulation. In an instructional simulation, students learn by actually performing activities to be learned in a context that is similar to the real world" (Lee 1999). A study of the simulations available indicated that it could be valuable to include simulation ideas in presentation of material. These factors were recognised in 1992 and a slow process of developing computer-based case studies was started. Until the emergence of the web these were largely text-based and delivered on the student network. Only recently have multimedia components been added and delivery made so that students can access the case studies from any web connection.

\section{THE DESIGN PROBLEM}

The creation of case studies for students of systems analysis has been an arduous task for many academics. A common strategy of those that produce their own case studies is to write about a fictitious business from personal experience of a real business. This often leads to the case study being structured around memories of the operations of a business rather than providing a rich environment in which the student can find use for skills they are developing. 
Our early case studies were small. This meant that several students would be given identical tasks to complete. Apart from a natural tendency of students to solve the problem by waiting for a good student to "find the answers" and then using that knowledge for their own solution, a small single case does not promote communication. We would like students to be saying "I have this problem with my area, did you have a similar problem and, if so, how did you approach the solution?"

A small case also has the problem that there is not much room for cooperative group work which is typical of real systems analysis projects.

Our "from memory" case studies were often realistic enough but segmenting the larger ones to allow for group work lead to some members of a group being given very trivial tasks with not much challenge in them. Our memories returned case studies with a single problem in them in one area: the area we solved when doing the real problem the first time.

Our early case studies had the designer clearly anxious to put information in that could be quickly put into one of the design diagrams we were teaching. Attempts to add sample data and other detail were difficult to achieve and normally were included not as sample data would normally occur, but to make sure students were guided to produce a particular "answer".

\section{TEAM WORK, CASE STUDY SIZE AND COMPLEXITY}

A particular constraint of case studies in systems analysis is the issue of teamwork. Systems analysts almost always work in teams due to the size and complexity of real life problems. It is our belief that teamwork can be taught, but can only be learned by working in a team and experiencing the problems of teams that are mentioned in the teaching.

It is unrealistic and unfair to expect students to learn new behaviours, form new relationships, and learn about new topics and methods in a short period of time, with the pressure of assessment and without guidance on social aspects of technology use, particularly when the technologies and the networks on which we rely for collaboration do not always function optimally.

\section{THE DESIGN STRATEGY}

Our solution which has evolved over a number of years involves the following activities: 
1. Clearly identifying the concepts to be addressed in the case study.

In this case: Basic entity modelling including identification of entities, attributes and relationships. Relationships to be one to one, one to many and many to many. Mandatory and optional relationships. Entity modelling involving supertypes and subtypes. Entity modelling involving recursive relationships.

2. Create a solution incorporating examples of the concepts.

In this case: We created an ER model containing 5 entities one of which contained subtypes and one of which contained a recursive relationship. The solution produced can also be used as the basis for the correction of student work.

3. Duplicate several possible solutions to essentially similar problems so that you can reduce the number of students working on the same problem thus reducing the ability to copy other student's solutions.

In this case: We created an ER model containing approximately 25 entities $(5 \times 5)$ covering five functional areas. Students could then be given one of 5 sets of data.

4. Work backwards from the solution to create the problem.

In this case: We needed to give broad hints as to the existence of entities, attributes and relationships particularly in regard to recursive relationships and super and sub types.

5. Problem definition to incorporate as much realism as possible through the use of multimedia components.

In this case: We used video tapes and still images for definitions and processes, audio tapes for business rules and forms for attribute identifications. Clues to identification of entities could be found in all four.

6. Create an interface which necessitates the use of investigative techniques to gain access to above components.

In this case: We use a simple web-based interface. This is the next step for improvement.

7. Allocate duplicate problems in a manner to minimise copying.

In this case: Final assignment consisted of a group assignment where each member would contribute their component to the construction of the whole. This required that each group member be working on a separate component thus essentially requiring each member of the group to be working on a different component than their closest friends normally the most common target for copying. Groups tend to be friendship based.

8. Investigate Web based delivery if appropriate.

In this case: All components were placed on the Web. 


\section{THE RESEARCH}

Over a two year period approximately 300 students were exposed to a hypermedia-based business case study delivered through the web. The case study underwent three iterations during this period, each time increasing the complexity of the business environment simulation. In the first case, "DD real estate" was a business using photographs of properties, scanned images of documents, Excel and Word documents and a web interface with almost no intelligence. The final case study includes video and sound files and has been fully designed using the structured approach outlined above.

Structured interviews of students, the teaching team and analysis of student results was used to gather data. This data sought to determine the extent to which the format of the business environment supported the establishment of systems analysis skills. Staff input was also used to test the effectiveness of the design strategy in producing the case study material.

\section{OUTCOMES OF THE RESEARCH}

Case study production has now been carried out over several courses in systems analysis for over 10 years. In this time we have measured the amount of learning in several ways, chiefly including teaching staff reflections and assessment material analysis. We have also measured the amount of output and time taken to produce that output in terms of total size of the case study.

In that time we have found a number of clear outcomes

1. Students respond to their assessment tasks in a different way from the past. Students show an involvement with the cases of much greater depth. This shows clearly in questions asked of the tutorial staff and the types of activity undertaken during construction of their systems.

2. Students produce solutions with a far greater depth of detail, more closely reflecting common business practice.

3. There are some indications of better learning. This can be seen in the level of difficulty in examination questions. This measure of success is difficult to quantify as pass rates for examination are kept fairly constant.

4. Since the start of this research in 1989 , several new staff members have been involved in subjects in which the techniques here have been used. Without exception the new staff report a greater satisfaction with the case studies produced and with their ability to contribute to the case study production. 


\section{CONCLUSION}

Sample problems can be placed on a web site for students to test and develop their learning. In the case of learning systems analysis this is particularly apt as the web is an ideal environment in which to encapsulate the complexity and fragmentation of information normally found in a business environment. Here we describe a technique for ensuring that a web site with this aim encapsulates all the aspects needed to ensure that a student is able to learn those skills intended to be included by the teacher.

1. Clearly identifying the concepts to be addressed in the case study.

2. Create a solution incorporating examples of the concepts.

3. Duplicate a number of possible solutions to essentially similar problems so that you can reduce the number of students working on the same problem thus reducing the ability to copy other student's solutions.

4. Work backwards from the solution to create the problem.

5. Problem definition to incorporate as much realism as possible through the use of multimedia components.

6. Create an interface which necessitates the use of investigative techniques to gain access to above components.

7. Allocate duplicate problems in a manner to minimise copying.

8. Investigate Web based delivery if appropriate.

\section{REFERENCES}

Choo, C. W. (1998). The Knowing Organization: How Organizations Use Information to Construct Meaning, Create Knowledge, and Make Decisions. New York, NY: Oxford University Press.

Gagne, E., Yekovich, C. W., \& Yekovich, F. (1993). The cognitive psychology of schooling learning. New York, Harper Collins.

Gayeski, D. M. (1993). Multimedia for Learning: Development, Application, Evaluation. NJ, Educational Technology Publication.

Jong, T. D. (1991). Learning and instruction with computer simulations. Education \& Computing, 6, 215-227

Lee J; (1999); Effectiveness of computer-based instructional simulation: A meta analysis International Journal of Instructional Media; New York;

Leidner, D. E., \& Jarvenpaa, S. L. (1995). The use of information technology to enhance management school education : A theoretical view. MIS Quarterly, 19(3), 265-292.

Liaw S., (2001) Designing the hypermedia-based learning environment International Journal of Instructional Media; New York ,28(1)

Maddux, C. D., Johnson, D. L., \& Willis, J. W. (1997). Educational Computing, Learning with Tomorrow's Technologies. 21 Edition. Allyn \& Bacon. Needham Height, MA.

Mangaliso, M. P. (1995). "The Strategic Usefulness of Management Information as Perceived by Middle Managers.” Journal of Management 21: 231-250. 
Simmonds P G ; Dawley D D; Ritchie W J ; Anthony W P; (2001) An exploratory examination of the knowledge transfer of strategic management concepts from the academic environment to practicing managers Journal of Managerial Issues; Pittsburg; Fall 2001;

Slavin, R. (1992). Cooperative learning. Encyclopedia of Educational Research. M. C. Alkin. New York, Macmillan: 235-238.

Vygotsky, L. S. (1978). Mind in Society. Cambridge MA, Harvard University Press.

Weisman, D. and W. P. Anthony (1999). "Strategies of Executive Learning: An Executive Learning Model." Proceedings of the Academy of Management, Chicago, IL.

Weert, T. J. V. (2003). Life-Long Learning in Virtual Learning Organisations. TelE-Learning. The Challenge for the Third Millenium. D. Passey; and M. Kendall;. London, Klewer Academic Publishers: 135-142. 